\title{
A comparison between alternative relocation options for the Pacific Islands based on a human-centred approach
}

\author{
Despina Linaraki
}

D. Linaraki

Cities Research Institute, Sea Cities, Griffith University, Queensland

Email: Despina.linaraki@griffithuni.edu.au

\begin{abstract}
Extreme weather conditions, rising sea levels, and floods will make many low-lying Pacific Islands uninhabitable by 2050. Frequent floods, affect food production and freshwater availability, enhance shoreline erosion, and cause the destruction of the coastal infrastructure. Current adaptation strategies require a considerable amount of funds, materials, technological and human resources. As a result, researchers argue that local adaptation strategies will continue for the next years, but relocation will be proved to be the most effective solution. Based on the argument above, this research paper is analysing the criteria for efficient relocation based on a human-centred approach and specifically on the notion of islandness. Following, it is comparing alternative relocation options for the Pacific Islands, as per the relocation criteria and the land availability. The analyses showed that the distance from the land of origin is critical for the efficiency of the relocation. The further the distance, the less effective the relocation will be.
\end{abstract}

Keywords: Relocation, Pacific Islands, Human-centred, Islandness, Expansion

\section{Introduction}

Researchers argue that around 200 million people who currently live on low-lying islands and coastal areas will have to relocate inland or in higher elevation countries by 2050 due to the climate change impacts (McLeman, 2011; Nunn, 2013; Perumal, 2018; Wyett, 2014). The consequences of climate change include extreme weather events and disasters, storms, cyclones and droughts, sea level rise, and floods (Ourbak \& Magnan, 2018). The frequency and intensity of these events will soon make some low-lying islands and coastal areas uninhabitable (Gemenne, 2011; Perumal, 2018). The latest predictions from the Intergovernmental Panel on Climate Change (IPCC) on sea level rise, project an average rise between $0.29 \mathrm{~m}$ to $1.10 \mathrm{~m}$ by 2100 (Oppenheimer, 2019). However, researchers argue that this prediction can rise to $2 \mathrm{~m}$ or even more, due to environmental and anthropogenic stressors (Bamber, 
Oppenheimer, Kopp, Aspinall, \& Cooke, 2019; NOAA, 2012). If sea level rises above 2m globally, many of the low-lying islands and coastal metropolis will be underwater (Jamero et al., 2017; Yamamoto \& Esteban, 2017). As a result, most of the Pacific Islands, Indian Ocean Islands, Caribbean Sea Islands and coastal cities around the world such as Amsterdam, Dubai, Abu Dhabi, Mumbai, New Orleans, Miami, Jakarta and Bangladesh will be affected (Connell, 2013; FloodMap, 2020).

\section{Pacific Islands' response to climate change}

This research is focusing on the low-lying Pacific islands due to their high rate of vulnerability. Specifically, among the 20 countries with the highest risk in the World Risk index on 2019, 11 are islands: Vanuatu, Antigua and Barbuda, Tonga, Solomon Islands, Papua New Guinea, Brunei Darussalam, Philippines, Cape Verde, Fiji, Timor-Leste, and Kiribati, while nine out of the 11 are specifically, Pacific Islands (Day et al., 2019). Research evidence has repeatedly indicated that these islands are expected to be severely impacted by climate change while some of them have already disappeared (Connell, 2015; Kueffer \& Kinney, 2017; Nunn, 2013; Walshe \& Stancioff, 2018).

\subsection{Geomorphological characteristics and the anthropogenic pressures}

The reason for the low-lying islands' vulnerability is mainly their natural geomorphological characteristics, along with the pressure from anthropogenic activities (Duvat \& Magnan, 2019; Royle, 2014; Wong, 2011; Woodroffe, McLean, Smithers, \& Lawson, 1999) (Fig.1). According to research evidence, $27 \%$ of the Pacific Islands have a maximum elevation distance of $5 \mathrm{~m}$ from the current sea level (Nunn, Kumar, Eliot, \& McLean, 2016). Consequently, even a small increase in sea level is immediately reducing the area above the surface of the water. At the same time, the shortage of land is reducing the defence to floods and storms because there is not efficient space to protect the inland areas. Moreover, limited available land leads to density and overpopulation. For example, Tarawa at Kiribati is over-dense and overpopulated with not efficient setbacks from the coastline, which increases its vulnerability to extreme events.

Moreover, one-third of the Pacific Islands are classified as reef islands, such as the Federated States of Micronesia, French Polynesia, Kiribati, Marshall Islands, and Tuvalu (Nunn et al., 2016). The reef islands have been creating as part of biogenic processes (Ramalho et al., 2013). Specifically, the low-lying coral islands' have been created from sediments produced by corals, coralline algae, foraminifera, molluscs and Halimeda (Kench, Owen, \& Ford, 2014). These islands' are extra vulnerable to coastal erosion, land loss and morphological changes, due to these unconsolidated biogenic structural materials (Jamero et al., 2019; Nunn, 2009a; Nunn et al., 2016; Webb \& Kench, 
2010). Another $39 \%$ of the Pacific islands have been created by volcanic activities (Nunn et al., 2016). Volcanic islands are not as vulnerable as reef islands. First, because they can extend higher than $5 \mathrm{~m}$, consequently, they do not have an immediate impact on land reduction due to sea level rise. Furthermore, constant lava production armours their perimeter. However, their geological formation is also easily affected by coastal erosion (Ramalho et al., 2013). As soon as volcanic activity ceases, the islands begin losing their durability, and they start sinking (Nunn \& Kumar, 2018; Weigelt, Jetz, \& Kreft, 2014). To conclude, more than two-thirds of the Pacific Islands will be affected by climate change. However, for the reasons analysed above, low-lying reef islands are found to be at the forefront of climate change impacts (Fig. 1).

\begin{tabular}{|l|l|l|}
\hline \multicolumn{2}{|c|}{$\begin{array}{c}\text { Vulnerability of Low-lying Pacific Islands } \\
\text { to climate change impacts }\end{array}$} \\
\hline \hline Unconsolidate materials & \multicolumn{1}{|c|}{ Land availability } & Low elevation heights \\
- Morphodynamic changes & - Overpopulation and density & - Frequent coastal flooding \\
- Unstable structures & - Unmanagable city planning & - Affected by sea level changes \\
- Vulnerable to erosion & - Limit the adaptation options & - Lack of mountains to protect \\
\hline
\end{tabular}

Fig. 1: This figure summarizes the vulnerability of low-lying Pacific Islands to climate change impacts, which is mainly resulted from the natural geomorphological characteristics and the anthropogenic pressures (Source: Nunn, 2009 and 2016 , Webb and Kench, 2010, Royle, 2014, Wong, 2011; Woodroffe, McLean, Smithers, \& Lawson, 1999).

\subsection{The impact of sea level rise and flood on food production and freshwater availability}

Except from the land erosion and vulnerability, climate change is also affecting food production and eliminates the freshwater, which is causing extra stress to the islanders. Specifically, the increase in carbon dioxide emission is lowering the ocean's PH and is causing acidification (Neill, 2015, p. 69). The decrease of the ocean's PH and the deoxygenation affect the coastal biodiversity, the species growth, and reproduction and impact the food chain (IPCC, 2014; Oppenheimer, 2019). Also, coral bleaching is affecting the food production that currently happens mostly on reef-bounded lagoons (Nunn, 2013). Moreover, saltwater intrusion due to sea level rise and floods is affecting the food production in many low-lying islands. Coastal flooding from waves extends far inland and saltwater intrusion can impact food production for months. Due to that reason, some communities have been forced to relocate, such as in parts of Papua New Guinea and Vanuatu (Piggott-McKellar, McNamara, Nunn, \& Sekinini, 2019). Moreover, frequent floods are affecting freshwater supply. For example, on the Island of Pele, 11 out of 23 groundwater wells were affected by salinization since 1990 (Perumal, 2018). In the Pacific Ocean, about 2.1 million people are expected to be affected by 2050 (Ash \& Campbell, 2016; Nunn, 2013). 


\subsection{Current adaptation strategies}

Current adaptation strategies that defend the coastal areas focus on protection, either by using seawalls, breakwaters, or dikes. Also, local adaptation methods include accommodation to the floods either by raising the infrastructures on stilts or by converting from agriculture to aquaculture (Jamero et al., 2019). At the same time, locals are exploring soft protection strategies, such as the replanting of mangroves along the coast to reduce storm impacts (Paeniu L, 2015).

The protection strategy each country uses is based on available funds, materials, technological, and human resources. Insufficient availability on any of them can lead to unstable constructions that damage both the environment and human lives' (Nunn, 2013). For example, research has proven that hard infrastructures are not as protective at low-lying Pacific Islands as they are on the Western countries (Nunn, 2009b, 2013; Oppenheimer, 2019). First, due to their design and material, hard protection strategies have been accused many times that instead of effectively protect the coastline, they reflect the wave energy and cause erosion in adjacent areas. Moreover, there is not enough available data at these areas for effective modelling of the protective infrastructure (Nunn, 2009b).

Also, the protection strategies against sea level rise and floods require an enormous amount of funds, not only because of the materials and construction but also because of the maintenance (Oppenheimer, 2019). People are spending billions of dollars every year towards the defence of the urban infrastructure. For example, it has been estimated that by 2040 the annual cost for adaptation strategies will be approximately USD 3 million in Palau, USD 17 million in Kiribati and USD 329 million in Fiji (WorldBank, 2016). Gathering this amount of funds is not easy, especially for the lowlying Pacific Islands, where the average income is very low. For example, in Kiribati, according to the World Bank, the annual income per capita is USD 1,625 (WorldBank, 2019).

At the same time, resources of materials for construction, such as sand, are being eliminated, causing extra stress to the impact of sea level rise and floods on islands (Oppenheimer, 2019). Consequently, at some point shortly, the funds, the human resources, and the sediment supplies will not be enough to protect coastal areas and especially the low-lying islands. Based on the argument above, researchers argue that relocation will be the most effective option for many Pacific Islands by the end of this century. In situ adaptation strategies will continue for the next 20 to 40 years, but locals will soon realize that relocation is their only effective solution (Nunn, 2013).

\subsection{The cases of Kiribati, Fiji and Vanuatu}

Kiribati is a significant example of a country in the middle of the Pacific Ocean, that is already facing multiple environmental challenges such as occasional floods and severe coastal erosion. It is composed 
of 33 reef islands (32 atolls and a raised coral island, known as Banaba) (Thomas, 2009). The unique geomorphological characteristics of Kiribati's reef islands make them extremely vulnerable to the climate change impacts and especially sea level rise and floods. First, the highest elevation point of most of Kiribati's islands is only $3 \mathrm{~m}$ above sea level (Wyett, 2014). Consequently, the projection of 1 or 2 meters of sea level rise will significantly reduce the available area of the low-lying islands. At the same time, most of Kiribati's atolls form a long and narrow strip (approximately a few meters to less than one kilometre) of land (Fig. 2). Therefore, in case of extreme events such as floods, there is not an available inland area that people could move to protect themselves. Also, the lack of mountains makes these areas completely unprotected from all the climatic events. Moreover, as referred above, these reef islands are composed of unconsolidated materials. As a result, they are vulnerable to morphological changes caused by environmental conditions (Biribo \& Woodroffe, 2013). Consequently, coastal erosion and floods are severely impacting this region.

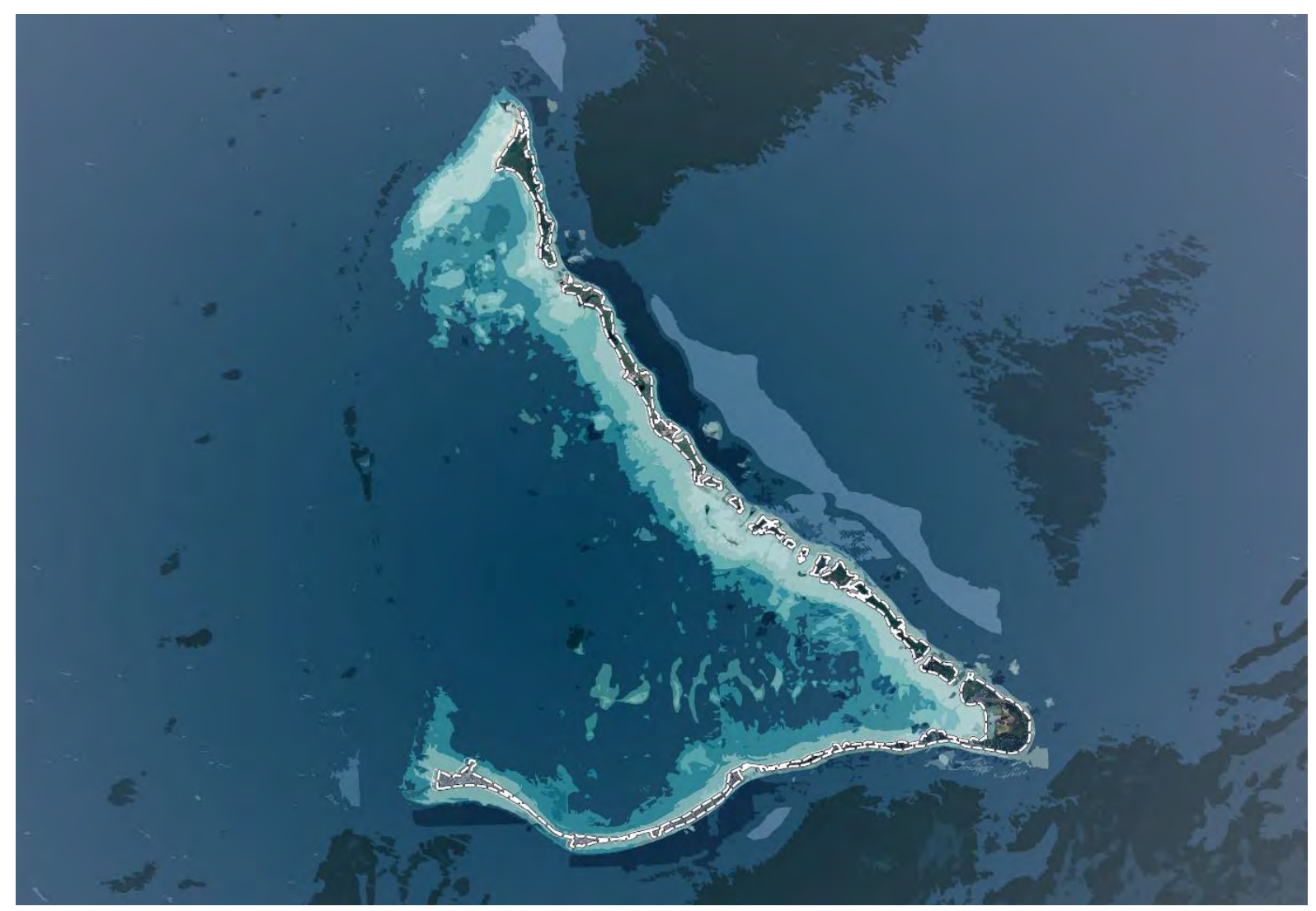

Fig. 2: Tarawa atoll, the capital of Kiribati, is formed by a long and narrow reef strip. (Source: D. Linaraki, adapted from Google Earth (C) 2020 Maxar Technologies)

According to Kiribati's government, current in situ adaptation strategies has not been proved to be successful (Wyett, 2014). At the same time, Kiribati's population is expected to increase to 
208,000 people by 2050 (Bedford, 2016). Most of these people will be distributed to South Tarawa, the capital of the Republic of Kiribati, in search of more opportunities. While future overpopulation is expected at Tarawa, researchers argue that Kiribati will need to relocate soon due to climate change (Wyett, 2014). However, there is not enough space for locals to move inland due to the narrow natural geomorphology of Tarawa (Fig. 3). The other atolls of Kiribati have similar geomorphological characteristics such as low elevation heights, comprised of narrow and long stripes of land, which immediately makes them vulnerable to sea level rise and floods.

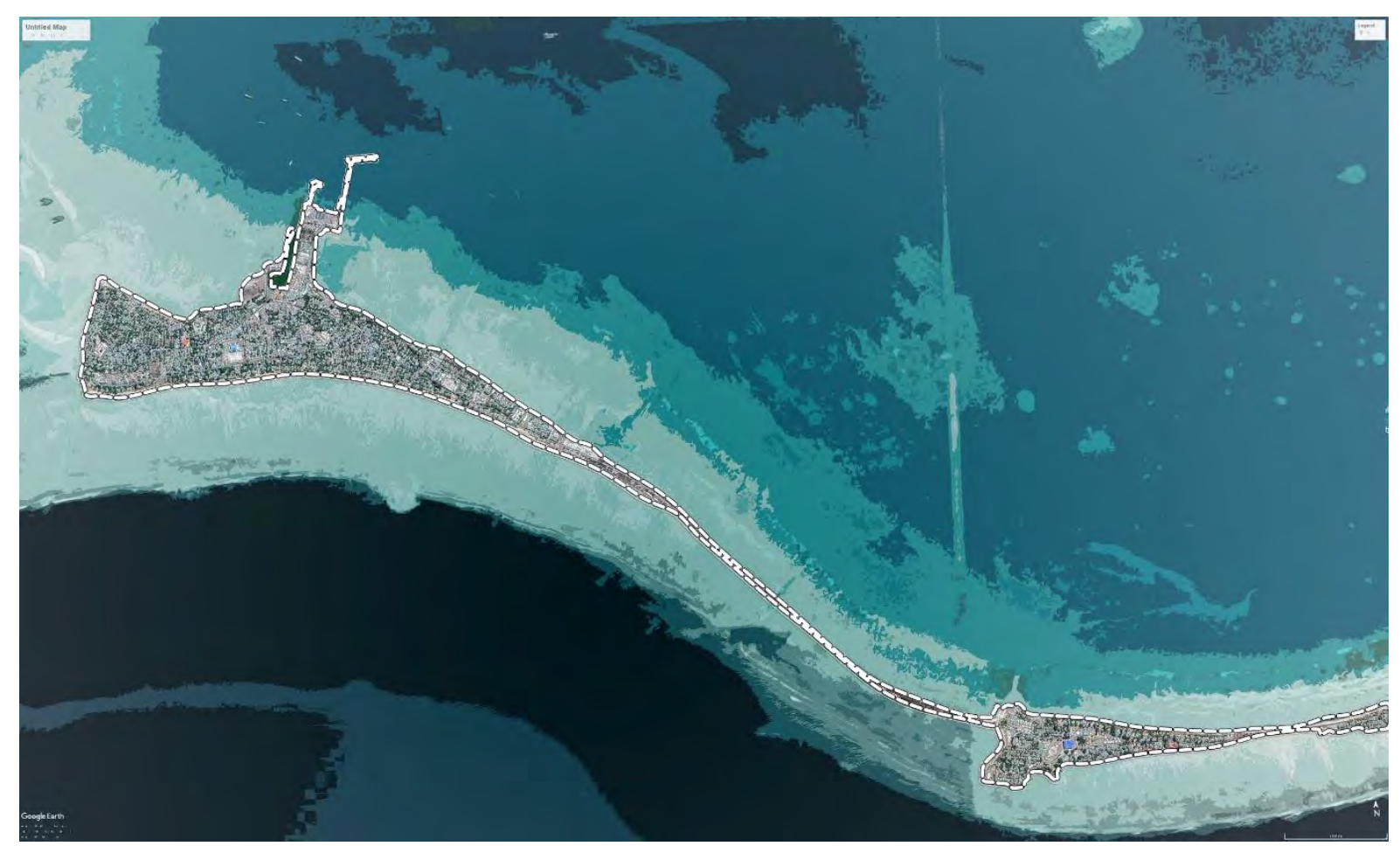

Fig. 3: South Tarawa atoll, Betio at the left and Bairiki at the right side as seen from satellite images. (Source: D. Linaraki, adapted from Google Earth (C) 2020 Maxar Technologies)

Consequently, the Government of Kiribati is preparing for future relocation in other countries. They have already purchased 6,000 acres of land in Naviavia, Fiji for USD 7 million to prepare for relocation (Jamero et al., 2017; Yamamoto \& Esteban, 2017). At the same time, Kiribati's government has started a program called "Migration with Dignity". This program aims to educate local citizens in order to be able to move and work in other countries (Yamamoto \& Esteban, 2017). However, even though the government of Kiribati is preparing a future relocation, Kiribati's residents do not wish to relocate from their islands, and they prefer in situ adaptation strategies (Wyett, 2014).

Similarly, to Tarawa, Viti Levu Island in Fiji is home to 28,000 people. According to predictions, at least half of the population will move by the end of this century (Piggott-McKellar et al., 
2019). The town of Nadi has experienced an increase in floods due to sea level rise, river infilling, deforestation, unmanaged coastline construction, and poor drainage. Researchers argue that the town will be uninhabitable in the next 15-20 years (Nunn, 2013). Adaptation strategies have been explored, such as river dredging, reforestation, or even redirection of the river delta, but still, based on the evidence that sea level is accelerating and extreme events will be more frequent, researchers argue that relocation will be their best option (Nunn, 2013).

At the same time, four indigenous communities at Fiji have already been relocated. The village of Vunidogoloa has been relocated $1 \mathrm{~km}$ inland due to erosion, floods and saltwater intrusion (Fig. 4). Similarly, Denimanu has relocated inland $(500 \mathrm{~m})$, to search for a better quality of life and food production. The relocation of both villages was effective. Locals got newly constructed houses and infrastructure, including solar power, rainwater tanks, fishponds, pineapple plants and household facilities (Jamero et al., 2019). Moreover, their new locations are within walking distance from their land of origin, consequently, locals were able to keep their everyday traditions such as food production and fishing (Piggott-McKellar et al., 2019). However, Denimanu new location is suffering from erosion and landslide issues that occurred after the construction of the new village (Piggott-McKellar et al., 2019).

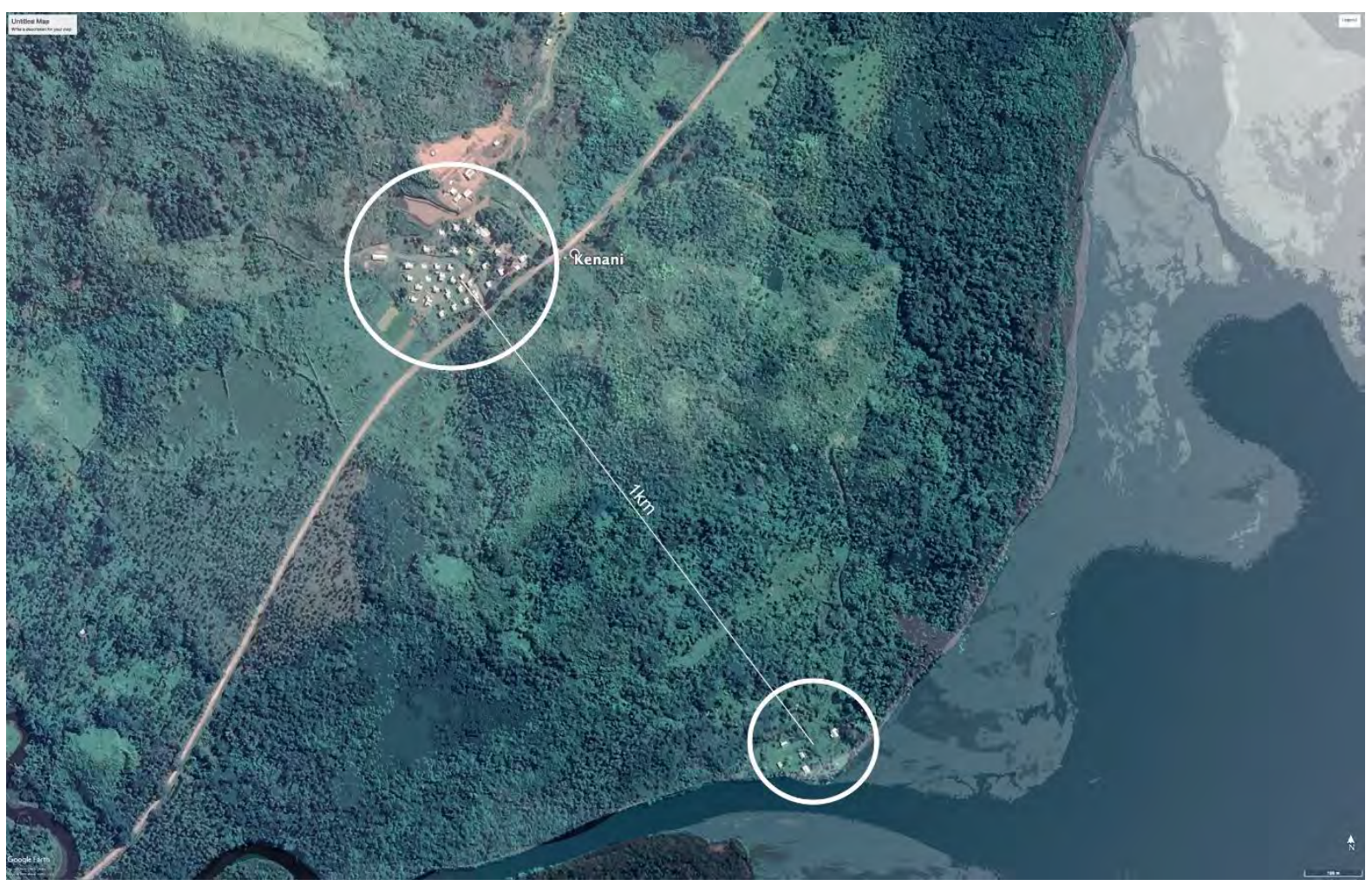

Fig. 4: Vunidogoloa village relocation to Kenani as seen from Google Earth on 2018. The original village location has been covered with vegetation. (Source: D. Linaraki, adapted from Google Earth @ 2020 Maxar Technologies) 
After experiencing extreme events, such as cyclones, floods and severe erosions, the Government of Fiji, released on 2018 relocation guidelines for the communities in need (Government, 2018). These guidelines were released to ensure that in the extreme scenario of relocation the cultures and livelihoods of the Fijians will remain intact. Furthermore, the Fijian government recognised over 80 communities in need of future relocation. Similarly, to Fiji, Vanuatu has developed guidelines on climate change and disaster-induced displacement strategies (Piggott-McKellar et al., 2019). Kiribati, Vanuatu and Fiji are at the forefront of climate change impacts due to their location, geomorphological characteristics and anthropogenic pressures. Frequent extreme events, sea level rise and floods are forcing the low-lying islands and coastal areas of Pacific to mandatory relocation.

\section{Human-centred approach and the notion of Islandness}

There is a need to determine whether relocation is an efficient option for islanders. As mentioned, due to climate change, many people will be forced to leave their homes, as low-lying islands and coastal areas will be marked uninhabitable. Many criteria need to be taken into consideration for efficient relocation. This research is identifying and analysing these criteria based on a human-centred approach and specifically on the notion of islandness. Islandness is a terminology that is used by many researchers worldwide to describe the state someone is while having lived on an island (Baldacchino, 2018). Research evidence suggests that islanders have developed a strong sense of community and a strong connection to their environment due to the physical isolation of the island (Conkling, 2007). The smaller and the more isolated the island, the bigger this connection exists. This feeling is accelerating because people depend to each other to survive. Consequently, based on the identity of islandness, the relocation of small villages or even whole islands can prove to be challenging for many reasons that are analysed below.

\subsection{Psychological, sociological and physiological impacts}

Relocating on different environments and intergrading into other cultures and societies can have significant psychological, physiological and sociological impacts. Research evidence has shown that immigrants experience unemployment, homelessness, landlessness and food insecurity (Barnett \& O'Neill, 2012; Tabucanon, 2012). Specifically, the relocation of Pacific Islanders is particularly difficult due to the fear of losing their identity and because of the cultural, social, political and economic costs that will be involved (Bukvic, 2018; Perumal, 2018). For example, people from the island of Tubigan were forced to relocate, after the 2013 earthquake that caused land subsidence and floods. However, they were opposed to relocation due to the fear that they will lose their livelihoods (Jamero et al., 2017). 
Another example comes from Maat people who were forced to relocate after a volcanic eruption. Most of them are still wishing to return to their ancestors' lands and are still considering themselves Ambrymese, even 15 years after the resettlement (Perumal, 2018). These psychological impacts are the results of islandness and particularly the strong connection that islanders have with their ancestors' land.

Another case of resettlement comes from Banabans, whom they relocated to Rabi island. Banabans started saving funds after they realize that their island would sooner or later run out of food due to extreme phosphate mining. After 30 years of savings, they started the relocation process in 1945. Banabans resettled on Rabu island. Rabu island provided more land, food, water, and material resources than the island of Banaban. Still, most of the refugees were reported unhappy. Especially the elderly was feeling depressed and hopeless. At the same time, people had to quickly adapt to new methods of food production, such as reef fishing and coconut plantation, a situation that caused them extra stress (Kumar, Terubea, Nomae, \& Manepora'a, 2006; Tabucanon, 2012). Except for the psychological issues, they experienced physiological challenges as well. The new island was wetter and colder than their island of origin. Immigrants were not prepared for this harsh winter. As a result, many people died from pneumonia (Tabucanon, 2012). Consequently, the relocation of Banabans was challenging not only because of psychological, but also because of physiological issues.

Similarly, researchers interviewed people from Vanuatu to find out if they would agree to relocate due to severe weather events. The results showed that in case they had to relocate, they would instead relocate inland so they could maintain their culture and livelihoods (Perumal, 2018). For islanders, moving away from their land means that they will lose their islandness and everything that this notion accompanies, such as their culture and livelihoods. The strong connection that they have with their ancestors' land and the water is severely affecting their emotions, and causing them psychological, sociological and physiological unbalances. In some extreme cases where relocation is unavoidable, islanders would instead relocate close to their land of origin, in environments like their current locations. Similar environments to their environments of origin could provide the security that their culture, social tights, and networks could be maintained the same (Perumal, 2018).

\subsection{Cultural disagreements}

Furthermore, many concerns have been raised both from the refugees and the hosts. One recent example comes from Fijians regarding the resettlement of people from Kiribati at Fiji. Locals are concerned that overpopulation will increase pollution in their area (Yamamoto \& Esteban, 2017). Similarly, the relocation from the island of Gaua to the island of Vanua Lava was unsuccessful due to cultural disagreements between the hosts and the guests (Perumal, 2018). 
Research evidence has shown that the hosts concern when it comes to migration issues. This feeling, which is known as xenophobia (derived from the Greek words $\xi \dot{\varepsilon} v o \zeta=$ foreigh and $\varphi o ́ \beta 0 \varsigma=$ fear), is being developed between living organisms, and it is resulting from biological uncertainties and the fear of the predator (Delanty, Wodak, \& Jones, 2011). The feeling of uncertainty is accelerating, especially when a large amount of people needs displacement, which is currently the case for most lowlying Pacific islands.

Moreover, the accommodation of a large group of people results in the loss of otherwise available land. This land was available for use from the host country either for agriculture or for accommodation. Furthermore, more people will have to use the same resources for freshwater, food, or material supply, which in the case of the small Pacific Islands are limited due to their small size and their extremely isolated locations. Integrating two societies into one, will be of a great challenge for the governments and the residents of Pacific Islands. When resettling and integrating into an existing society, new uncertainties will occur due to different environments, societies, and cultures between the residents. Consequently, for Pacific islanders, relocating into environments where the integration of two different societies will not be necessary would be more efficient.

\subsection{Global agreements for Pacific Islands}

In addition, currently, there is no agreement between counties to accommodate climate change refugees. Consequently, there is a big concern about where and how Pacific islanders will relocate (Yamamoto \& Esteban, 2017). The United States of America is granting access to some of the Pacific islands. This agreement is known as the Compact of Free Association (COFA), and it involves the Federal States of Micronesia, Marshall Islands and Palau. Similarly, New Zealand grants access to the Cook Islands, Tokelau and Niue (Ash \& Campbell, 2016). Besides, to the USA, many experts argue that Pacific islanders should relocate to Australia and New Zealand (Tabucanon, 2012).

Australia has been seen many times in history as a place to resettle people in need because there is plenty of available habitable space both inland and on the coastal zones. However, most of this available space is unproductive, since more than half of the surface is composed of a desert. For example, Nauruans were offered relocation to Australia, New Zealand, or the United Kingdom, but they declined the offer due to the fear of losing their identity (Tabucanon, 2012; Tabucanon \& Opeskin, 2011). Relocating people from a small island to a vast continent is not a convenient solution. Topological differences are resulting in livelihood changes. Specifically, islanders have learned to live close to the water. As a result, their culture and livelihood have been developed based on water. Consequently, if the new area is not close to the water, it will result in losing their livelihood. 


\subsection{Funds}

Furthermore, relocation requires many funds to be successful. The process of relocation in a new land requires cost for preparation, construction of infrastructure and moving expenses of the families. Also, the further the distance from the land of origin, the more the cost for the relocation (Campbell, 2014). Gathering a huge amount of funds is not an easy task, especially for Pacific islanders, where the average income is in the limits of poverty. It has been estimated that the cost of relocation in Fiji could be as high as USD 10,000 per household, which will include land acquisition and building of infrastructure and moving (Oppenheimer, 2019). However, according to the World Bank, the annual income per capita at Fiji is USD 6,267, a lot less than the relocation cost (WorldBank, 2019). Consequently, for relocation to take place, locals should use external funds and donors. However, many times, donors make their own decisions without considering the needs of the people. To sum up, relocation cost can create extra pressure on the islanders. It is important to notice that relocating as close as possible to the land of origin, reduces the relocation expenses.

\subsection{Efficient relocation criteria}

Consequently, deciding the place for relocation is equally crucial to the process itself. Based on the analyses described above, relocating as close as possible, in environments similar to the land of origin, could be proven to be beneficial for Pacific islanders. Whereas, relocating people due to climate change, in other countries could be challenging, mainly because of the strong notion of islandness. As described above, the strong connection that Pacific islanders have with their land, the water and their culture could derive psychological, sociological and issues in case of relocation. In addition, the impact of relocation cost, the cultural differences and the legal agreements between the places are equally crucial. Moreover, relocation criteria should cover the basic needs for human survival and development, such as food production, freshwater availability, security, shelter construction, health and employment. All these criteria should be taken into consideration when decisions are taken for relocation (Fig. 5). 


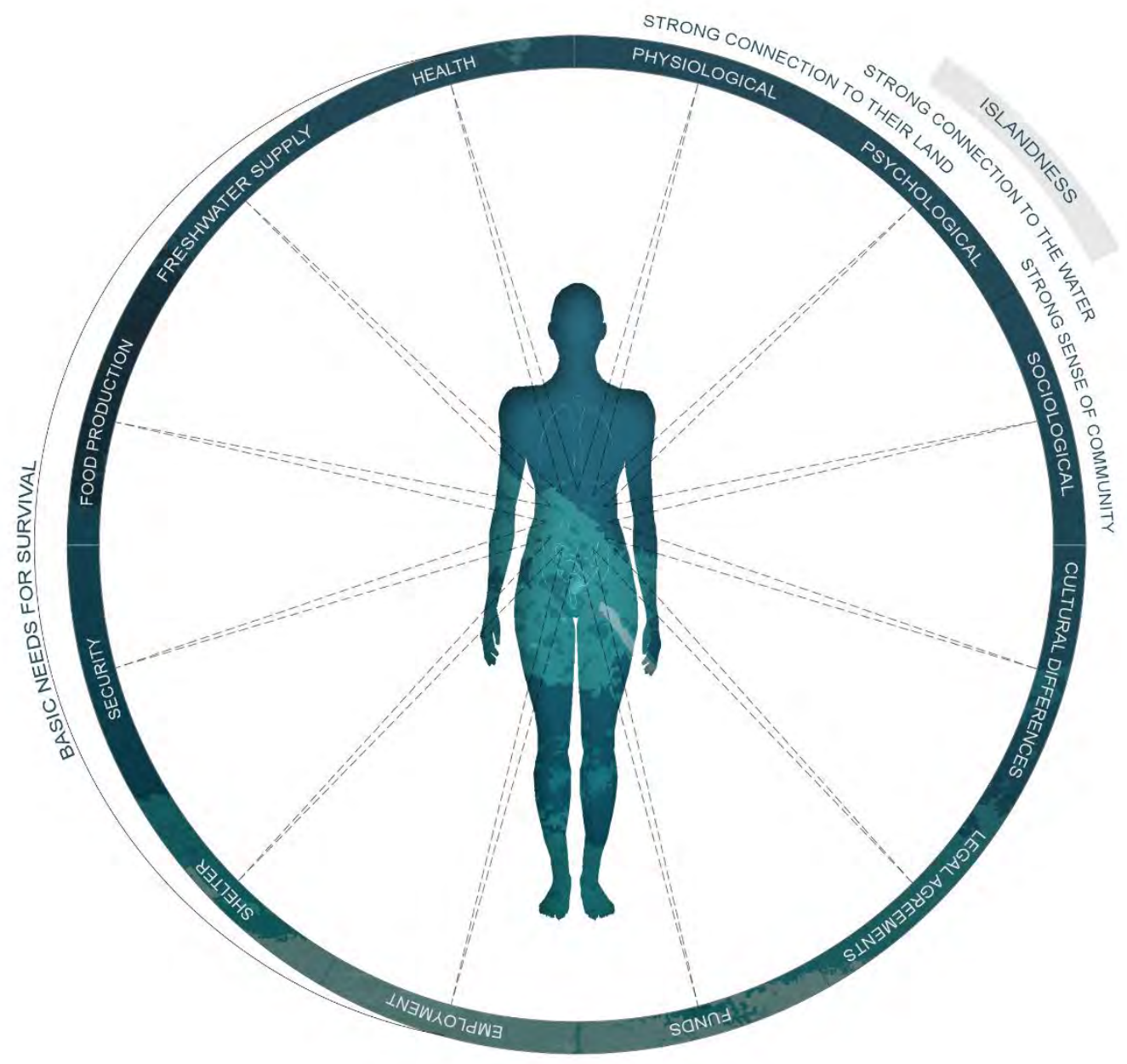

Fig. 5: This diagram represents the criteria that should be taken into consideration in case of relocation. These criteria are based on a human-centred approach and specifically on the notion of islandness.

\section{Relocation options}

Taking into consideration the urgency of the low-lying islands and coastal areas of Pacific to relocate, this research is exploring relocation scenarios that respond to the criteria analysed above. The relocation options that exist vary according to the available land resources of the affected country (Fig. 6). For example, for coastal areas that are part of larger islands, it is relatively easy to relocate inland, because there is available space like it happened with the relocation of Vunidogoloa. Similarly, in some islands, there is the possibility to relocate in higher elevations, such as Apia in Samoa, Honiara in the Solomon 
Islands or Sura in Fiji (Nunn, 2013). Sikaianans and Ontong Java are also considering relocating to higher elevations (Connell, 2013). However, even if there is available land for relocation, it may not be habitable. For example, Avarua at the Cook Islands or Pago Pago in American Samoa, even if there is available space in higher altitudes, the landscape is so steep that it is not convenient for humans to live there (Nunn, 2013). A significant example that was mentioned earlier is the relocation of Denimanu. The new relocation area has been proved to be unsuitable for habitation due to the landslide issues that occurred afterwards.

Particularly for low-lying reef islands relocation inland is often inconvenient since there is not enough available land. Also, most of the reef islands, as discussed above, have a maximum elevation of $3 \mathrm{~m}$ above sea level, which immediately makes them vulnerable to sea level rise and floods. As a result, they are unsuitable for relocation. Furthermore, limited land resources for agriculture and limited freshwater have opposed a scenario of internal relocation. Consequently, in case there is no available land, people have to relocate to other cities or other countries, as it happened with the case of Banabans.

However, in case of relocation, people have opposed a scenario of moving in other cities or countries, integrating with other cultures or moving in environments different from their current environments, where they would have to readapt their livelihoods and cultures. Consequently, this research argues that if there is no available land for relocation, adaptation strategies should focus on expansion, to enhance the opportunity for relocation as close as possible to their current land and the water (Fig. 6).

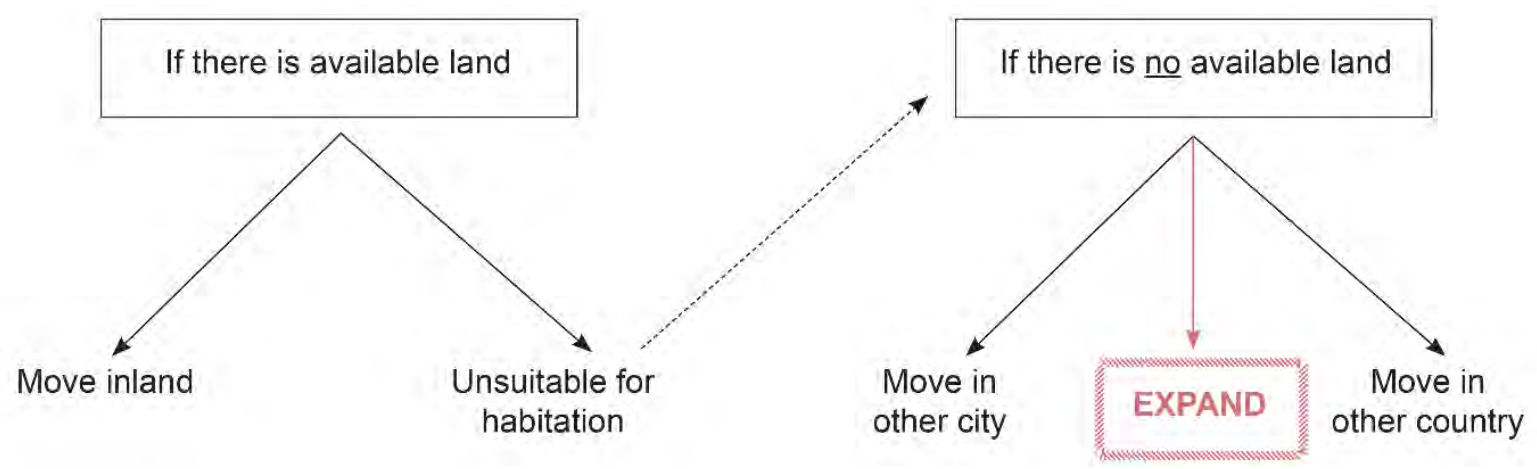

Fig. 6: Relocation scenarios. If there is available land, people can move inland in higher elevations. However, even if there is available land, this land is not always suitable for relocation. If there is no available land, people will have to move to other cities or other countries. Whereas, this research suggests expanding, to create available land for habitation close to the land of origin. 


\subsection{Expansion}

Three strategies are examined in this research and are associated with expansion into the water. First is about horizontal expansion in the water, to create protection barriers and to increase the land resources. The second strategy is about vertical expansion by raising the inland area in order to relocate people in higher elevations. The third option is to create new islands as close as possible to the islands of origin that could accommodate the immigrants (Fig. 7). The selection should be based on available land resources and suitable environmental conditions.

First, expanding horizontally in the water could create a protective barrier to eliminate the wave action before reaching the coastal infrastructure. In this way, it can protect the coastal areas from extreme events and frequent flooding, while at the same time, it increases the available land. The expansion could be done by using soft infrastructure, for example, by the planting of vegetation such as mangroves or by expanding the reef zones. Currently, many Pacific Islands are following the strategy of planting vegetation as a defence system (Paeniu L, 2015). However, the areas that are located in low elevation heights will eventually need to relocate in higher elevations due to sea level rise. Also, for the horizontal expansion to act as a protective barrier, the new land should extend far inshore to dissipate the wave energy successfully.

The second scenario is to expand vertically. By raising and levelling the inland areas, people could move in higher elevation. As a result, they could be protected from rising sea levels and floods. At the same time, the affected coastal area could be released to the water, creating in this way a big wetland, which would protect the inland areas. The existing infrastructure materials and land resources could be reused to elevate the inland areas. This method could be proven efficient, for low-lying islands with available land resources but not enough elevation height.

The third concept is to create a new island close to the island of origin. This option could be effective when there is no available land to move inland or in higher elevations, for example in the case of Tarawa, Kiribati. In the case of Tarawa atoll, a new island in the middle of the lagoon, would be protected from waves by the long and narrow strips of the perimeter zone (Fig. 2). In case of fully relocation, the affected area would become a wetland and be used for aquaculture, while like the second scenario, the existing materials and land resources could be reused to create the new land. 


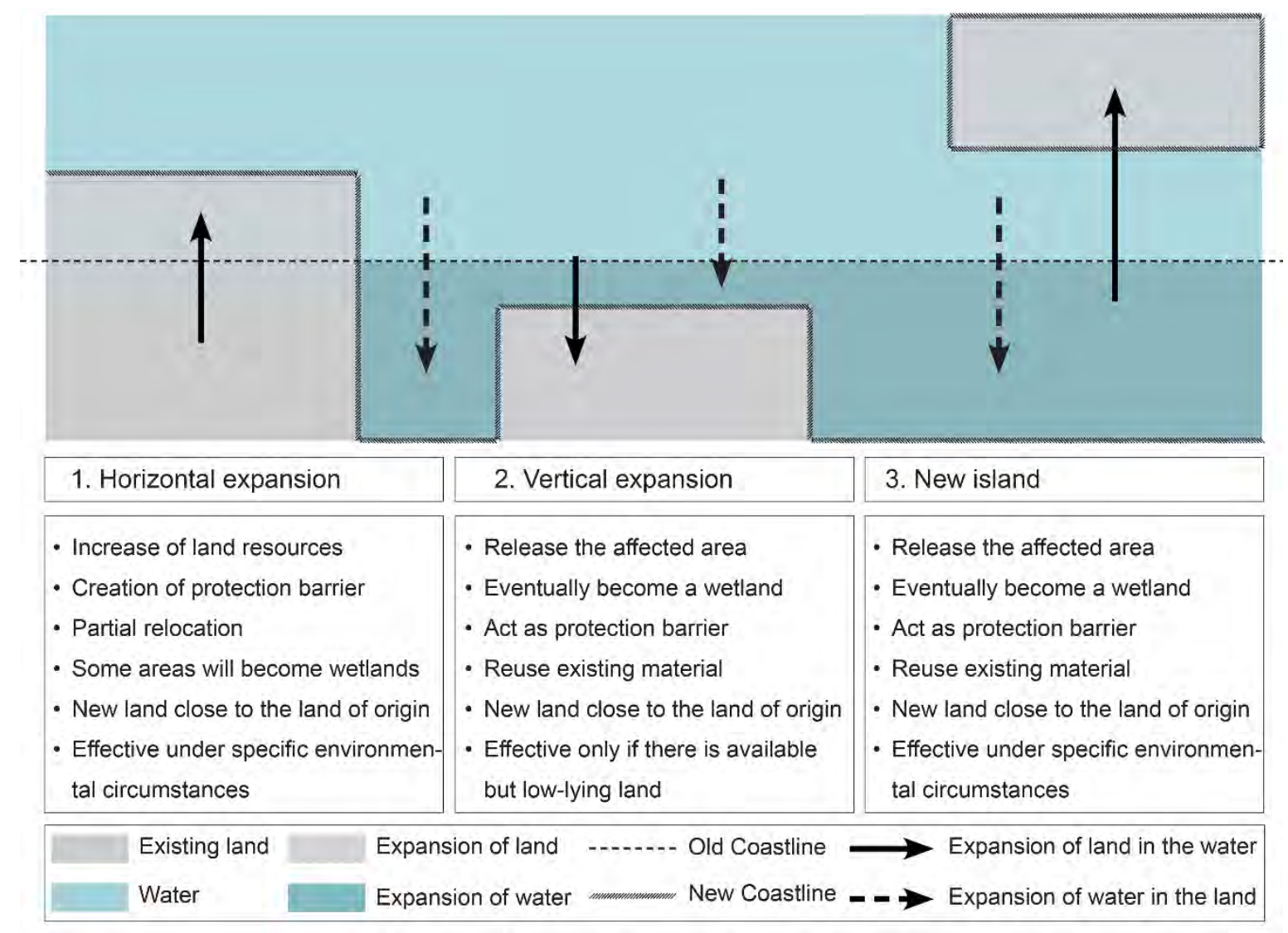

Fig. 7: Expansion scenarios in plan view. The first option shows the scenario of horizontal expansion in the water. The second is about the vertical expansion of inland areas, and the third concept is about the creation of a new island and the release of the existing land to nature.

There are many advantages, as well as limitations following this strategy. As argued above, by developing the strategy of expansion, people could relocate closer to their land of origin. However, to create a new land that could accommodate the whole village or the island, would require a considerable amount of funds, materials and technological resources, which are not always available to the Pacific islands. The challenge of these concepts is to create new land by using the minimum requirements of funds and resources. Moreover, the design of the new land should take into consideration the environment. Pacific islands are unique, biodiverse environments that host significant aquatic and terrestrial living organisms (Berry \& Gillespie, 2018) and need to be protected in case of new land creation. Consequently, the new land should not extend on top of existing ecosystems and should not overexploit the natural resources for the construction.

Also, there is many times the case where unmanageable expansion in the water creates more problems for the community instead of eliminating them. For that reason, the construction method and morphology of the land expansion have a significant role as well. For example, in Tarawa Atoll, the capital of Kiribati, people used land reclamation in order to connect or extend the reef islands. These 
solid fill lands limit lagoonal flushing and cause erosion (Biribo \& Woodroffe, 2013). Similarly, in Mumbai, people connected the original seven islands with debris, stopping in this way, the natural flow of water and causing erosion and pollution (Zope, Eldho, \& Jothiprakash, 2017). In a similar vein, Dubai's palm islands were accused of pollution, due to the stagnate waters that resulted from the enclosed shape of the construction (Martín-Antón, Negro, José María del, López-Gutiérrez, \& Esteban, 2016). Consequently, materials, construction methods, and morphology should be equally considered for the concept of land expansion.

\section{Conclusion -further discussion}

This research analyses the relocation options for Pacific islanders based on a human-centred approach. As argued, efficient relocation should take into consideration the notion of islandness and provide the basic needs for survival. The analyses showed that the distance from the land of origin is critical for the efficiency of the relocation. The further the distance, the less effective the relocation would be. Moreover, the environment of the new land has an essential part in maintaining the islandness. Relocating people as close as possible to their land of origin in environments similar to their current environments could keep their culture and livelihood intact. However, based on the available land resources, relocation close to their land is not always achievable. That is the case on many low-lying reef islands. Consequently, this research argues that if there is no available land, adaptation strategies should focus on expansion.

\section{References}

Ash, J., \& Campbell, J. (2016). Climate change and migration: the case of the Pacific Islands and Australia. Journal of Pacific Studies (ERA 2012, 2015, 2018 Journal(s) Listed), 36(1), 53-72.

Baldacchino, G. (2018). The Routledge International Handbook of Island Studies. Routledge.

Bamber, J. L., Oppenheimer, M., Kopp, R. E., Aspinall, W. P., \& Cooke, R. M. (2019). Ice sheet contributions to future sea-level rise from structured expert judgment. PROCEEDINGS OF THE NATIONAL ACADEMY OF SCIENCES OF THE UNITED STATES OF AMERICA, 166(23), 11195-11200. doi:10.1073/pnas.1817205116

Barnett, J., \& O'Neill, S. J. (2012). Islands, resettlement and adaptation. Nature Climate Change, 2(1), 8-10. doi:10.1038/nclimate1334

Bedford, R. (2016). Population change and migration in Kiribati and Tuvalu, 2015-2050 : hypothetical scenarios in a context of change. New Zealand population review, 42, 103-134.

Berry, A. J., \& Gillespie, R., G. . (2018). Evolution. In The Routledge International Handbook of Island Studies: Routledge.

Biribo, N., \& Woodroffe, C. D. (2013). Historical area and shoreline change of reef islands around Tarawa Atoll, Kiribati. Sustainability Science, 8(3), 345-362. doi:10.1007/s11625-013-0210-z 
Bukvic, A. (2018). Towards the sustainable climate change population movement: the Relocation Suitability Index. Climate and Development, 10(4), 307-320. doi:10.1080/17565529.2017.1291407

Campbell, J. R. (2014). Climate-Change Migration in the Pacific. The Contemporary Pacific, 26(1), 128. doi:10.1353/cp.2014.0023

Conkling, P. (2007). On Islanders and Islandness. Geographical Review, 97(2), 191-201. doi:10.1111/j.1931-0846.2007.tb00398.x

Connell, J. (2013). Soothing Breezes? Island perspectives on climate change and migration. Australian Geographer, 44(4), 465-480. doi:10.1080/00049182.2013.852497

Connell, J. (2015). Vulnerable Islands: Climate Change, Tectonic Change, and Changing Livelihoods in the Western Pacific. The Contemporary Pacific, 27(1), 1-36. doi:10.1353/cp.2015.0014

Day, S. J., Forster, T., Himmelsbach, J., Korte, L., Mucke, P., Dr. Radtke, K., ... Weller, D. (2019). WorldRiskReport 2019, Focus: Water Supply. Retrieved from https://reliefweb.int/sites/reliefweb.int/files/resources/WorldRiskReport2019_Online_english.pdf

Delanty, G., Wodak, R., \& Jones, P. (2011). Identity, Belonging and Migration. Liverpool: Liverpool University Press.

Duvat, V. K. E., \& Magnan, A. K. (2019). Rapid human-driven undermining of atoll island capacity to adjust to ocean climate-related pressures. Scientific Reports, 9(1), 15129-15116. doi:10.1038/s41598-019-51468-3

FloodMap. (2020). Flood Map. Retrieved from www.floodmap.net

Gemenne, F. (2011). Climate-induced population displacements ina $4^{\circ} \mathrm{C}+$ world. Philosophical Transactions of the Royal Society A: Mathematical, Physical and Engineering Sciences, 369(1934), 182-195. doi:10.1098/rsta.2010.0287

Government, F. (2018). Fiji: Planned Relocation Guidelines - A framework to undertake climate change related relocation. Retrieved from https://cop23.com.fj/wpcontent/uploads/2018/12/CC-PRG-BOOKLET-22-1.pdf

IPCC. (2014). Climate Change 2014 Synthesis Report Summary for Policymakers. Retrieved from https://www.ipcc.ch/site/assets/uploads/2018/02/AR5_SYR_FINAL_SPM.pdf

Jamero, M. L., Onuki, M., Esteban, M., Billones-Sensano, X. K., Tan, N., Nellas, A., . . Valenzuela, V. P. (2017). Small-island communities in the Philippines prefer local measures to relocation in response to sea-level rise. Nature Climate Change, 7(8), 581-586. doi:10.1038/NCLIMATE3344

Jamero, M. L., Onuki, M., Esteban, M., Chadwick, C., Tan, N., Valenzuela, V. P., . . Avelino, J. E. (2019). In-situ adaptation against climate change can enable relocation of impoverished small islands. Marine Policy, 108, 103614. doi:10.1016/j.marpol.2019.103614

Kench, P. S., Owen, S. D., \& Ford, M. R. (2014). Evidence for coral island formation during rising sea level in the central Pacific Ocean. Geophysical Research Letters, 41(3), 820-827. doi:10.1002/2013GL059000

Kueffer, C., \& Kinney, K. (2017). What is the importance of islands to environmental conservation? Environmental Conservation, 44(4), 311-322. doi:10.1017/S0376892917000479

Kumar, S., Terubea, T., Nomae, V. D., \& Manepora'a, A. (2006). Poverty and Deprivation amongst Ethnic Minorities in Fiji: The Case of Ni Solomoni and Rabi Islanders. Fijian Studies: A Journal of Contemporary Fiji, 4(1), 125-142.

Martín-Antón, M., Negro, V., José María del, C., López-Gutiérrez, J. S., \& Esteban, M. D. (2016). Review of coastal Land Reclamation situation in the World. Journal of Coastal Research, 1(75), 667-671. doi:10.2112/SI75-133.1

McLeman, R. A. (2011). Settlement abandonment in the context of global environmental change. Global Environmental Change, 21(1), S108-S120. doi:10.1016/j.gloenvcha.2011.08.004

Neill, P. (2015). The Once and Future Ocean, Notes towards a new hydraulic society. Maine: Leete's Islands Books. 
NOAA. (2012). Global Sea Level Rise Scenarios for the United States National Climate Assessment (OAR CPO-1). Retrieved from

Nunn, P. D. (2009a). ISLAND FORMATION. In (1 ed., pp. 490): University of California Press.

Nunn, P. D. (2009b). Responding to the challenges of climate change in the Pacific Islands: management and technological imperatives. Climate Research, 40(2/3), 211-231. doi:10.3354/cr00806

Nunn, P. D. (2013). The end of the Pacific? Effects of sea level rise on Pacific Island livelihoods. Singapore Journal of Tropical Geography, 34(2), 143-171. doi:10.1111/sjtg.12021

Nunn, P. D., Kumar, L., Eliot, I., \& McLean, R. F. (2016). Classifying Pacific islands. Geoscience Letters, 3(1), 1-19. doi:10.1186/s40562-016-0041-8

Nunn, P. D., \& Kumar, R. (2018). Origins and environments. In The Routledge International Handbook of Island Studies: Routledge.

Oppenheimer, M., B.C. Glavovic, J. Hinkel, R. van de Wal, A.K. Magnan, A. Abd-Elgawad, R. Cai, M. Cifuentes-Jara, R.M. DeConto, T. Ghosh, J. Hay, F. Isla, B. Marzeion, B. Meyssignac, and Z. Sebesvari. (2019). Sea Level Rise and Implications for Low-Lying Islands, Coasts and Communities. In: IPCC Special Report on the Ocean and Cryosphere in a Changing Climate. Retrieved from Monaco:

Ourbak, T., \& Magnan, A. K. (2018). The Paris Agreement and climate change negotiations: Small Islands, big players. Regional Environmental Change, 18(8), 2201-2207. doi:10.1007/s10113017-1247-9

Paeniu L, I. V., Jacot Des Combes H, De Ramon N'Yeurt A, Korovulavula I, Koroi A, Sharma P, Hobgood N, Chung K and Devi A. (2015). Coastal Protection: Best Practices from the Pacific. Retrieved from

Perumal, N. (2018). "The place where I live is where I belong": Community perspectives on climate change and climate-related migration in the Pacific island nation of Vanuatu. Island Studies Journal, 13(1), 45-64. doi:10.24043/isj.50

Piggott-McKellar, A., McNamara, K., Nunn, P., \& Sekinini, S. (2019). Moving People in a Changing Climate: Lessons from Two Case Studies in Fiji. Social Sciences, 8(5), 133. doi:10.3390/socsci8050133

Ramalho, R. S., Quartau, R., Trenhaile, A. S., Mitchell, N. C., Woodroffe, C. D., \& Ávila, S. P. (2013). Coastal evolution on volcanic oceanic islands: A complex interplay between volcanism, erosion, sedimentation, sea-level change and biogenic production. Earth-Science Reviews, 127, 140-170. doi:10.1016/j.earscirev.2013.10.007

Royle, S. A. (2014). Islands: nature and culture. London: Reaktion Books.

Tabucanon, G. M. (2012). The Banaban Resettlement: Implications for Pacific Environmental Migration. Pacific Studies, 35.

Tabucanon, G. M., \& Opeskin, B. (2011). The Resettlement of Nauruans in Australia: An Early Case of Failed Environmental Migration. The Journal of Pacific History, 46(3), 337-356. doi:10.1080/00223344.2011.632992

Thomas, F. R. (2009). Historical Ecology in Kiribati: Linking Past with Present. Pacific Science, 63(4), 567-600. doi:10.2984/049.063.0406

Walshe, R. A., \& Stancioff, C. E. (2018). Small Island perspectives on climate change. Island Studies Journal, 13(1), 13-24. doi:10.24043/isj.56

Webb, A. P., \& Kench, P. S. (2010). The dynamic response of reef islands to sea-level rise: Evidence from multi-decadal analysis of island change in the Central Pacific. Global and Planetary Change, 72(3), 234-246. doi:10.1016/j.gloplacha.2010.05.003

Weigelt, P., Jetz, W., \& Kreft, H. (2014). Bioclimatic and physical characterization of the world's islands (vol 110, pg 15307, 2013). PROCEEDINGS OF THE NATIONAL ACADEMY OF SCIENCES OF THE UNITED STATES OF AMERICA, 111(51), 18400-18400. doi:10.1073/pnas.1422548112

Wong, P. P. (2011). Small island developing states. Wiley Interdisciplinary Reviews: Climate Change, 2(1), 1-6. doi:10.1002/wcc.84 
Woodroffe, C. D., McLean, R. F., Smithers, S. G., \& Lawson, E. M. (1999). Atoll reef-island formation and response to sea-level change: West Island, Cocos (Keeling) Islands. Marine Geology, 160(1), 85-104. doi:10.1016/S0025-3227(99)00009-2

WorldBank. (2016). Climate and Disaster Resilience. Retrieved from http://pubdocs.worldbank.org/en/720371469614841726/PACIFIC-POSSIBLE-Climate.pdf

WorldBank. (2019). GDP per capita (current US\$) - Pacific island small states. Retrieved from https://data.worldbank.org/indicator/NY.GDP.PCAP.CD?amp\%3Bview=map\&locations=S2

Wyett, K. (2014). Escaping a Rising Tide: Sea Level Rise and Migration in Kiribati. Asia and the Pacific Policy Studies, 1(1), 171-185. doi:10.1002/app5.7

Yamamoto, L., \& Esteban, M. (2017). Migration as an Adaptation Strategy for Atoll Island States. International Migration, 55(2), 144-158. doi:10.1111/imig.12318

Zope, P. E., Eldho, T. I., \& Jothiprakash, V. (2017). Hydrological impacts of land use-land cover change and detention basins on urban flood hazard: a case study of Poisar River basin, Mumbai, India. Natural Hazards, 87(3), 1267-1283. doi:10.1007/s11069-017-2816-4 